\title{
DIVERGENCE OF MECHANISMS AND THE EFFECT ON THE FATIGUE LIFE VARIABILITY OF RENE` 88 DT
}

\author{
M. J. Caton ${ }^{1}$, S. K. Jha ${ }^{2}$, A. H. Rosenberger ${ }^{1}$, and J. M. Larsen ${ }^{1}$ \\ ${ }^{1}$ Air Force Research Laboratory, Materials and Manufacturing Directorate; AFRL/MLLMN Wright-Patterson AFB, Dayton, OH 45433, \\ USA \\ ${ }^{2}$ Universal Technology Corporation; 1270 N. Fairfield Rd., Dayton, OH 45432, USA
}

Keywords: nickel, superalloy, Rene 88 , fatigue, variability, crack nucleation

\begin{abstract}
In safely and cost-effectively managing aging turbine engine components, it is important to understand the inherent variability in the fatigue behavior of superalloy systems. The variability in fatigue life was investigated in Rene' 88 DT, a superalloy used widely in a number of critical turbine engine components for which low cycle fatigue is typically the life-limiting factor. Loadcontrolled, axial fatigue testing was performed at $593^{\circ} \mathrm{C}$ and 10 $\mathrm{Hz}$ on specimens taken from a pancake forging. A stress-life (S$\mathrm{N}$ ) curve was established where numerous tests were performed at single stress levels in order to determine cumulative probability of failure. It is observed that the variability in cycles to failure increases with decreasing stress level. In addition, as the variability in life increases, a separation of individual populations can be identified within the full population of failed specimens, suggesting that different failure mechanisms control the fatigue performance of the separate populations. It is proposed that the application of separate probability functions based upon the divergent failure mechanisms provides more accurate predictions of the variability of fatigue performance and reduces unnecessary conservatism.
\end{abstract}

\section{Introduction}

The Engine Rotor Life Extension (ERLE) initiative of the Air Force is examining the potential to safely extend the useful lifetime of turbine engine components through the introduction of improved life-management technologies. A key approach to such life extension involves the development of a better understanding of the variability in the fatigue behavior of superalloys and the sources driving this variability. Recent studies on titanium $[1,2]$ and $\gamma$-TiAl [3] based alloys showed that variability in fatigue life is due to the existence of competing failure mechanisms. A mechanism-based life prediction methodology was proposed and was shown to significantly reduce the uncertainty in total fatigue lifetime [1]. The study outlined in this paper investigates the variability in fatigue lifetimes of Rene' 88 DT specimens and examines the applicability of the approach presented in References 1-3.

Several studies have characterized the fatigue behavior of powderprocessed superalloys [4-7]. Huron and Roth [5] observed crack nucleation exclusively from intrinsic nonmetallic inclusions located subsurface in Rene' 88 DT fatigue specimens tested at $649^{\circ} \mathrm{C}$. At a lower temperature of $204^{\circ} \mathrm{C}$, a shift in mechanisms was observed, where initiation occurred exclusively from crystallographic facets within grains located at the specimen surface. Chang et al. [4] reported crack nucleation in Rene' 95 from voids, crystallographic facets, and several types of nonmetallic inclusions of varied shapes and sizes. This study illustrated that the character, size, shape and location of crack nucleation site significantly influences the fatigue life in powderprocessed superalloys. Hyzak and Bernstein [6, 7] characterized the fatigue crack initiation in the powder-processed superalloys AF-115 and AF2-1DA, revealing nucleation from pores, nonmetallic inclusions, and crystallographic facets. A distinct transition was identified in both alloys, where initiation shifted from surface to subsurface sites, with subsurface initiation occurring below a critical loading level and resulting in longer lifetimes. While these and other studies provide a comprehensive outline of the multiple microstructural features and mechanisms dominating the fatigue properties of powder superalloys, the literature provides little discussion on the variability in fatigue behavior. This paper examines the variability observed in fatigue performance of Rene' 88 DT with a focus on identifying the role different mechanisms play in driving the variability.

\section{Experimental}

The material examined in this study is Rene' 88 DT, a powder processed superalloy that is solution treated above the $\gamma^{\prime}$ solvus temperature. The nominal composition of Rene' 88 DT is given in Table 1. All of the specimens tested in this study were taken from a single pancake forging. The microstructure of the material is illustrated in Figure 1. Figure 1a shows the grain structure and illustrates that a significant number of twin boundaries are observed. Grain sizes range roughly from 10 to 40 $\mu \mathrm{m}$. Figure $1 \mathrm{~b}$ shows the precipitate structure within the material. The precipitates seen in this figure are $\gamma^{\prime}$ that formed during cooling from the solutionizing temperature (i.e., secondary $\gamma^{\prime}$ ). There is no primary $\gamma^{\prime}$ in the microstructure, due to the supersolvus solution treatment. It can be seen that the secondary $\gamma^{\prime}$ is roughly cuboidal in shape. Due to the scale of the micrograph, Figure $1 \mathrm{~b}$ does not reveal the tertiary $\gamma$ ' that formed during aging, since these precipitates will be on the order of 0.015 $\mu \mathrm{m}$ in diameter [8]. Monotonic testing at $593^{\circ} \mathrm{C}$ revealed an elastic modulus of $176 \mathrm{GPa}$ and $0.2 \%$ offset yield strength of 985 $\mathrm{MPa}$.

Table I. The nominal composition of Rene` 88 DT (Weight Percent)

\begin{tabular}{|c|c|c|c|c|c|c|c|c|c|c|}
\hline $\mathrm{C}$ & $\mathrm{C}$ & $\mathrm{M}$ & $\mathrm{W}$ & $\mathrm{Al}$ & $\mathrm{Ti}$ & $\mathrm{N}$ & $\mathrm{B}$ & $\mathrm{C}$ & $\mathrm{Zr}$ & $\mathrm{Ni}$ \\
$\mathrm{o}$ & $\mathrm{r}$ & $\mathrm{o}$ & & & & $\mathrm{b}$ & & & & \\
\hline 13 & 1 & 4 & 4 & 2. & 3. & 0. & 0.01 & 0.0 & 0.0 & $\mathrm{ba}$ \\
& 6 & & & 1 & 7 & 7 & 5 & 3 & 3 & 1 \\
\hline
\end{tabular}

Cylindrical, button-head specimens were tested at $593^{\circ} \mathrm{C}$ using a servo-hydraulic test frame. Testing was conducted under load 
control at $10 \mathrm{~Hz}$ with a stress ratio $(\mathrm{R})$ of 0.05 . The temperature

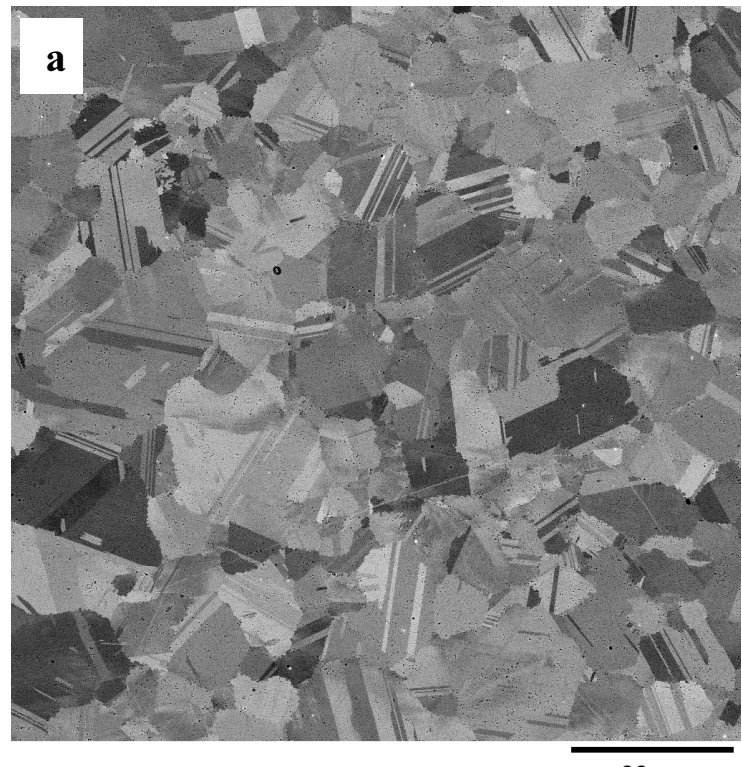

$60 \mu \mathrm{m}$

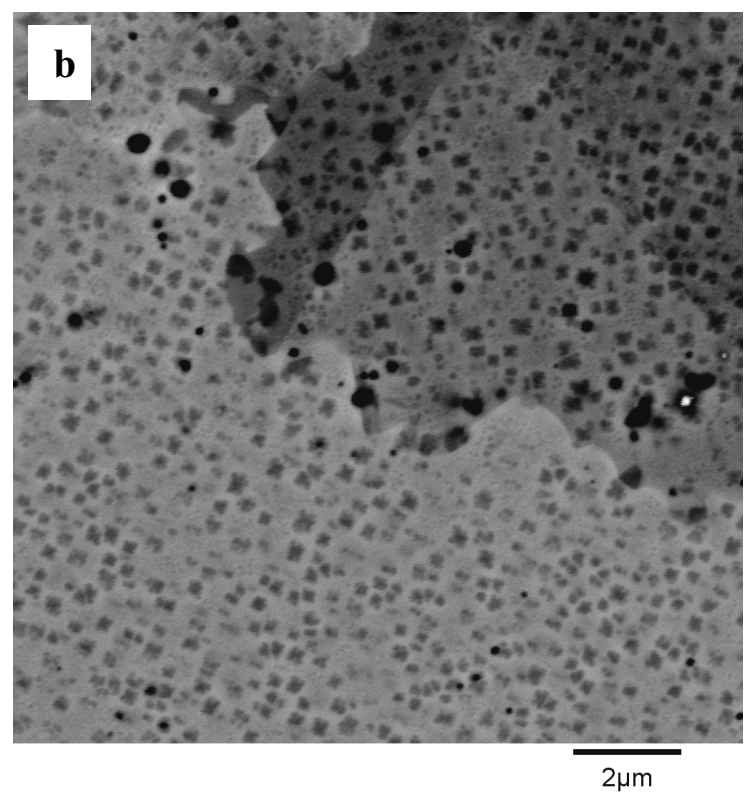

Fig 1: Micrographs of the Rene' 88 DT examined in this study illustrate (a) the grain structure and (b) the precipitate structure.

resistance furnace, and thermocouples placed outside of the gage section monitored the specimen temperature. A high temperature extensometer was used to record the strain within the gage section of the specimens and to document hysteresis loops throughout the fatigue life. The fracture surfaces of all specimens were examined using scanning electron microscopy to identify and characterize the crack initiation sites.

Specimens were machined to the dimensions shown in Figure 2, and the gage section was low stress ground. In order to establish baseline fatigue behavior and eliminate any influence of surface residual stresses, the gage length of all fatigue specimens was electropolished, removing approximately $50 \mu \mathrm{m}$ of material. of the specimens was controlled to $+/-5^{\circ} \mathrm{C}$ using an electrical Based upon residual stress depth profiles, it was determined that this was adequate to remove all compressive residual stresses resulting from low stress grinding. Electropolishing was conducted at $-50^{\circ} \mathrm{C}$ in a solution consisting of $61 \%$ methanol, $33 \% \quad 2$ butoxy ethanol, and $6 \%$ perchloric acid $(60 \%$ concentration). Specimens were slowly rotated in this solution under 19 volts for roughly 7 to 8 hours.

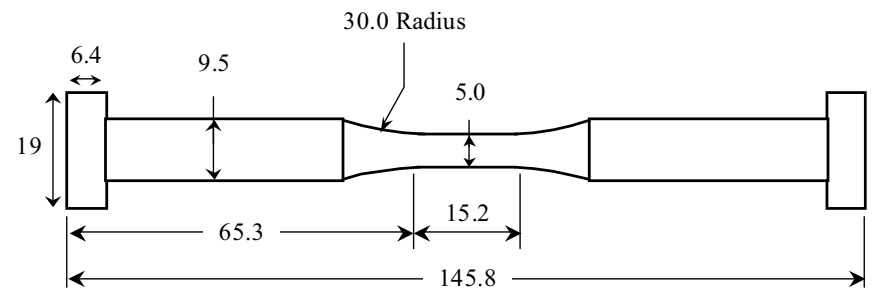

Fig 2: The cylindrical, button-head specimen used in this study. All dimensions are in millimeters.

\section{Results and Discussion}

\section{$\underline{\text { Cyclic Stress-Strain Behavior }}$}

The cyclic stress-strain behavior with respect to cycles at the stress levels $\left(\sigma_{\max }\right)$ of 940 and $1000 \mathrm{MPa}$ are presented in Figure 3. As shown, the alloy cyclically hardened within the first few cycles at these stress levels. The shift of the stress-strain hysteresis with cycles indicates strain accumulation at the global scale. Several superalloys [9, 10], including Rene' 88 DT [9], have been known to exhibit a serrated yielding behavior. However, this behavior is seen only in specific ranges of strain rate and temperature [9]. Also, this behavior has been studied in strain-controlled tests, mostly in monotonic studies and in a few fatigue studies. Our fatigue tests were done in load-control, and the effect of serrated yielding was manifested as sharp perturbations in the strain behavior. This is shown in Figure 4 at the $\sigma_{\max }$ level of $1200 \mathrm{MPa}$. The scale of strain perturbations seen at the onset of serrated yielding in Figure 4 is not a true measure of strain, but rather an indication of the inability of the test system to respond accurately to this behavior. It is, however clear that the effect of serrated yielding disappeared within the first few cycles due to rapid hardening.

The presence or absence of serrated yielding in the present study is superimposed on the results by Huron [9] in Figure 5. Huron's study was based on monotonic strain-controlled experiments. Since our fatigue tests were conducted in load-control, pseudo strain rate values derived from the first fatigue cycle have been plotted in the figure. As shown in Figure 5, Huron reported serrated yielding behavior within a band of temperatures ranging from 400 to $593^{\circ} \mathrm{C}$ and strain rates ranging from $1 \times 10^{-5} / \mathrm{sec}$ to $0.1 / \mathrm{sec}$. The temperature of $593^{\circ} \mathrm{C}$ was on the borderline of this band where serrated yielding was not seen in all cases. In our study, the effect of serrated yielding was seen at $\sigma_{\max }$ levels equal to or greater than $1200 \mathrm{MPa}$, and no serrated yielding was observed at $940 \mathrm{MPa}$. For stress levels between these values, serrated yielding was observed in only a few specimens (3 out of 9 tests at $\sigma_{\max }=1100 \mathrm{MPa}$ and 2 out of 14 tests at $\sigma_{\max }=1000$ $\mathrm{MPa}$ ). However, the effect of serrated yielding disappeared within the first few cycles in all cases. 

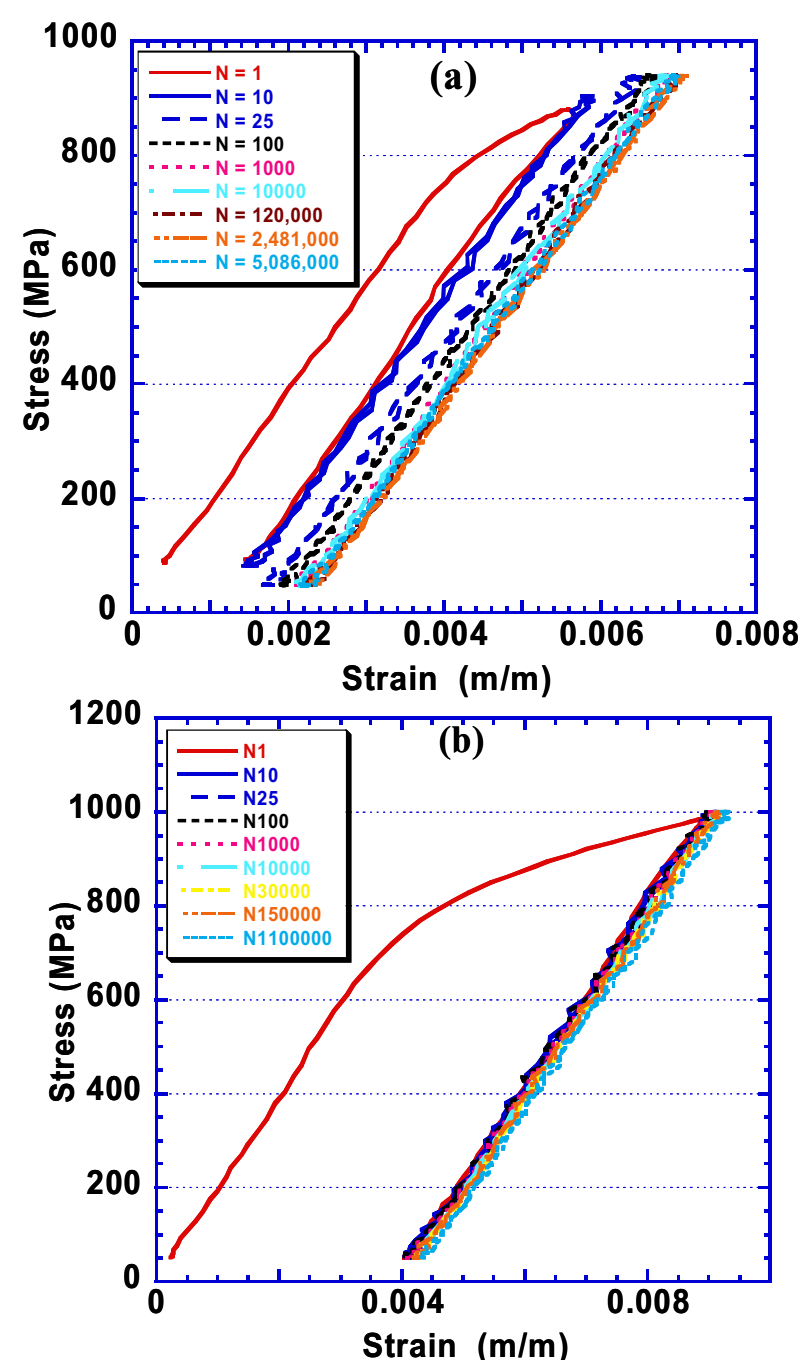

Fig 3: The cyclic stress-strain behavior of Rene' 88 DT at (a) $\sigma_{\max }$ $=940 \mathrm{MPa}$ and (b) $\sigma_{\max }=1000 \mathrm{MPa}$.

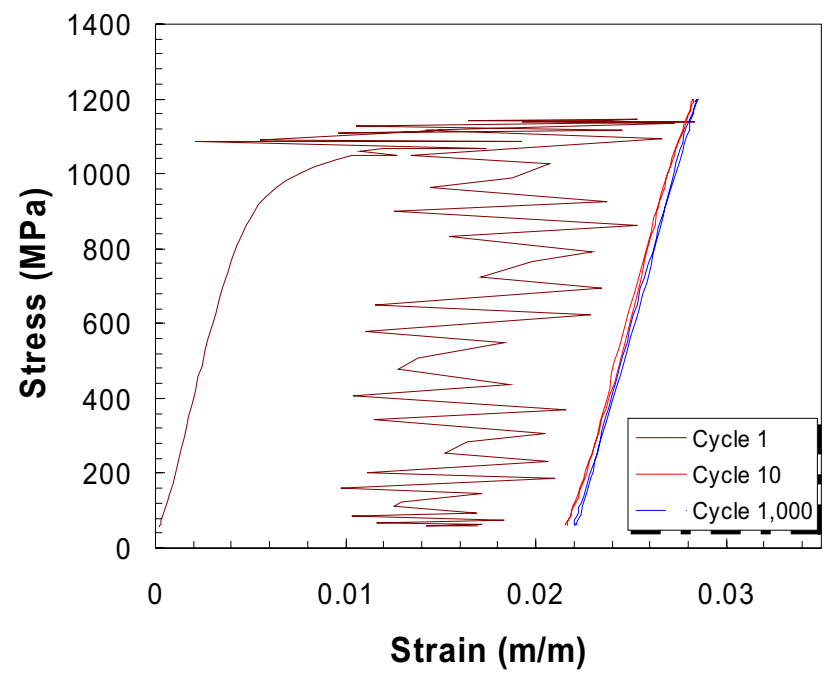

Fig 4: Effect of serrated yielding on the first fatigue cycle at $\sigma_{\max }$ $=1200 \mathrm{MPa}$

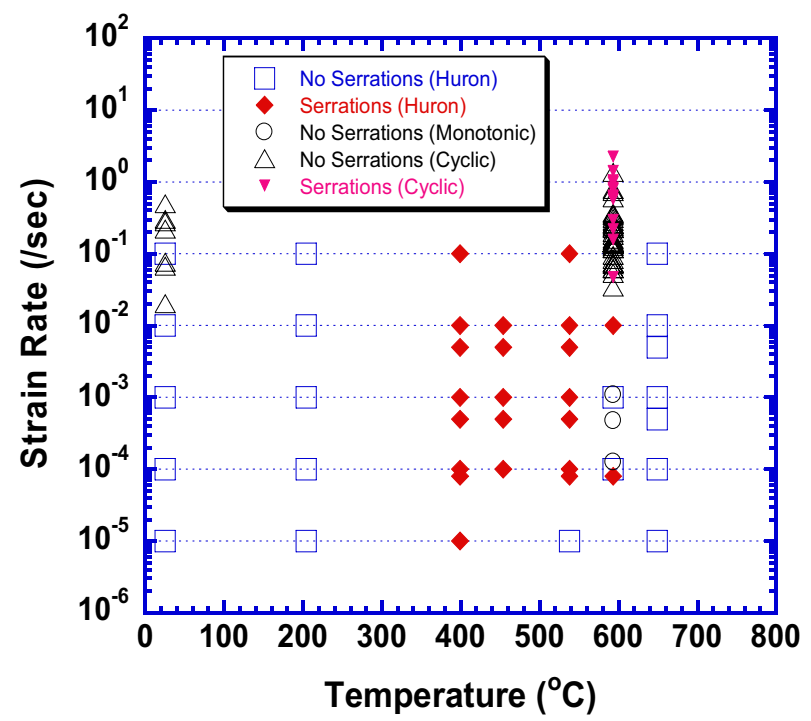

Fig 5: Conditions of temperature and strain rate under which serrated yielding is observed in Rene' 88 DT. Results from the current study are compared to results reported by Huron [9].

\section{Fatigue Life Behavior}

Surface vs. Subsurface Crack Nucleation. The fatigue life behavior of Rene $88 \mathrm{DT}$ at $593^{\circ} \mathrm{C}$ and the frequency of $10 \mathrm{~Hz}$ is shown in Figure 6. As indicated, all failures occurred by subsurface crack nucleation, with the single exception of the test at $\sigma_{\max }=1400 \mathrm{MPa}$. This was in spite of the removal of surface residual stress by electropolishing. Subsurface crack nucleation in superalloys has been reported in earlier studies $[4-7,11,12]$. In strain-controlled tests on the powder metallurgy ( $\mathrm{P} / \mathrm{M})$ superalloys AF-115 and AF2-1DA, Hyzak \& Bernstein [6, 7] reported a transition strain level $\left(\Delta \varepsilon_{\mathrm{t}} \sim 0.6\right.$ to $\left.0.7 \%\right)$, below which the failure initiation sites shifted from surface locations to subsurface locations. It is possible that in the present case the surface vs. subsurface crack nucleation transition exists between 1200 and $1400 \mathrm{MPa}$, which corresponds to pseudo strain ranges of $\Delta \varepsilon_{\mathrm{t}} \sim$ 0.65 to $0.87 \%$.

Variability in Life. It is clear from Figure 6 that the apparent variability in life increases with decreasing stress level. At the higher stress level of $1100 \mathrm{MPa}$, the range in fatigue lifetimes is roughly a factor of 3 , whereas the range in lifetimes at $940 \mathrm{MPa}$ is well over an order of magnitude. The fatigue failures are most commonly described by the lognormal probability density function (PDF) [13-16]. The corresponding cumulative distribution functions (CDF) or the probability of failure (POF) with respect to cycles for the $\sigma_{\max }$ levels of 940,1000, and 1100 $\mathrm{MPa}$ are shown in Figure 7. A decrease in the slope of the CDF with decrease in $\sigma_{\max }$ indicates the increase in the scale of variability. However, a poor agreement between the CDF and the experimental points is also evident at $\sigma_{\max }=940 \mathrm{MPa}$. It is interesting that if the CDFs are extrapolated to a POF of $0.1 \%$ (1 in 1000) a lower life will be predicted for the lower stress level of $940 \mathrm{MPa}$ than for $\sigma_{\max }$ of 1000 or $1100 \mathrm{MPa}$. This anomalous prediction indicates that the increase in the variability may not be arbitrary but governed by physical mechanisms that need to be 
understood. This type of behavior with decreasing stress level was seen in our earlier study on an $\alpha+\beta$ titanium alloy $[1,2]$. The experimental points formed a step-like shape with respect to the $\mathrm{CDF}$ at lower stress levels. This was concluded to be due to superposition of two failure mechanisms. Although more experimental points are needed in the present study, it is interesting to note a step-like shape of data at $\sigma_{\max }=940 \mathrm{MPa}$ as indicated by dashed lines (Figure 7). This seems an indication of divergent mechanisms producing the variability in fatigue lifetimes in this material.

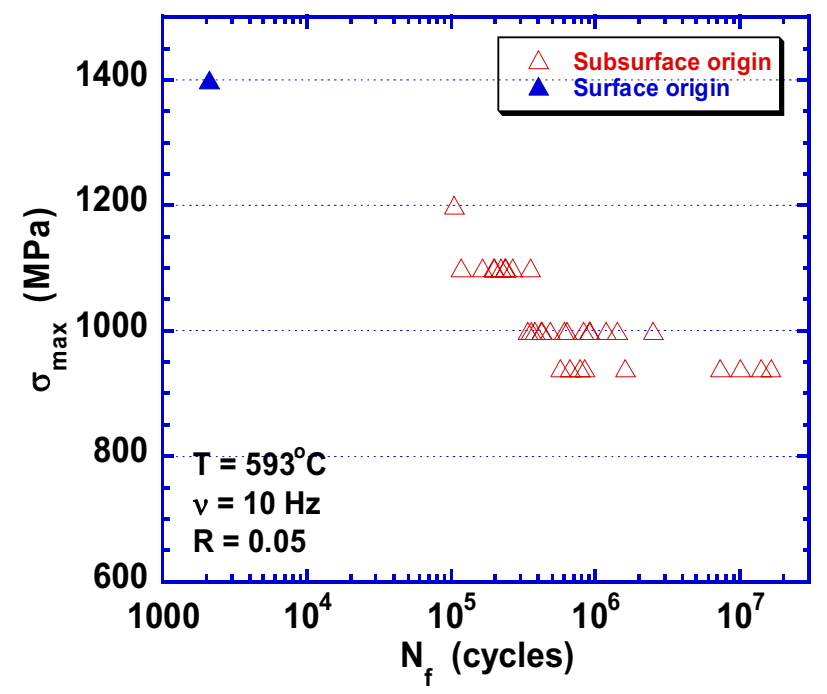

Fig 6: Fatigue life behavior of Rene` 88 DT.

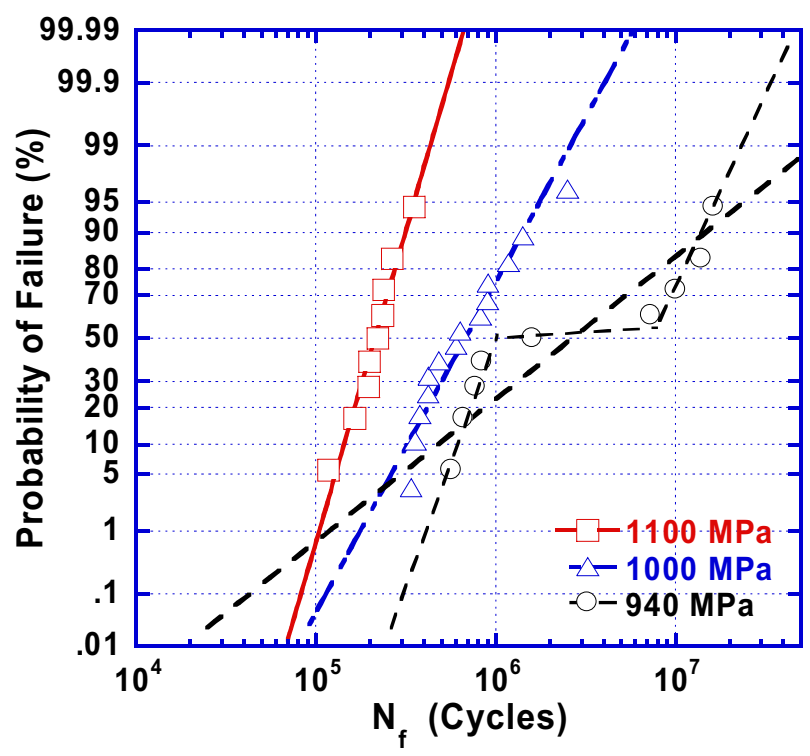

Fig 7: Plot of cumulative distribution functions (CDF) at selected stress levels

\section{$\underline{\text { Crack Nucleation Modes }}$}

Figures 8 and 9 show the fracture surfaces for specimens tested at $\sigma_{\max }=940 \mathrm{MPa}$ with fatigue lives of 664,580 and $7,322,863$ cycles, respectively. Figures 10 and 11 show the fracture surfaces for specimens tested at $\sigma_{\max }=1000 \mathrm{MPa}$ with fatigue lives of 632,985 and 825,463 cycles, respectively. Each of these figures includes a lower magnification photo showing the location of subsurface crack origin and a corresponding high magnification fractograph highlighting the crack nucleation area (CAN), marked by a dashed line. The high magnification fractographs illustrate the two types of crack nucleation sites that were observed: (i) crack nucleation from an inclusion (Figures $8(\mathrm{~b})$ and 10(b)) and (ii) crack nucleation across a crystallographic plane (Figures 9(b) and 11(b)). The size of the crystallographic and the inclusion CNAs appear to be similar in these figures. However, while lives
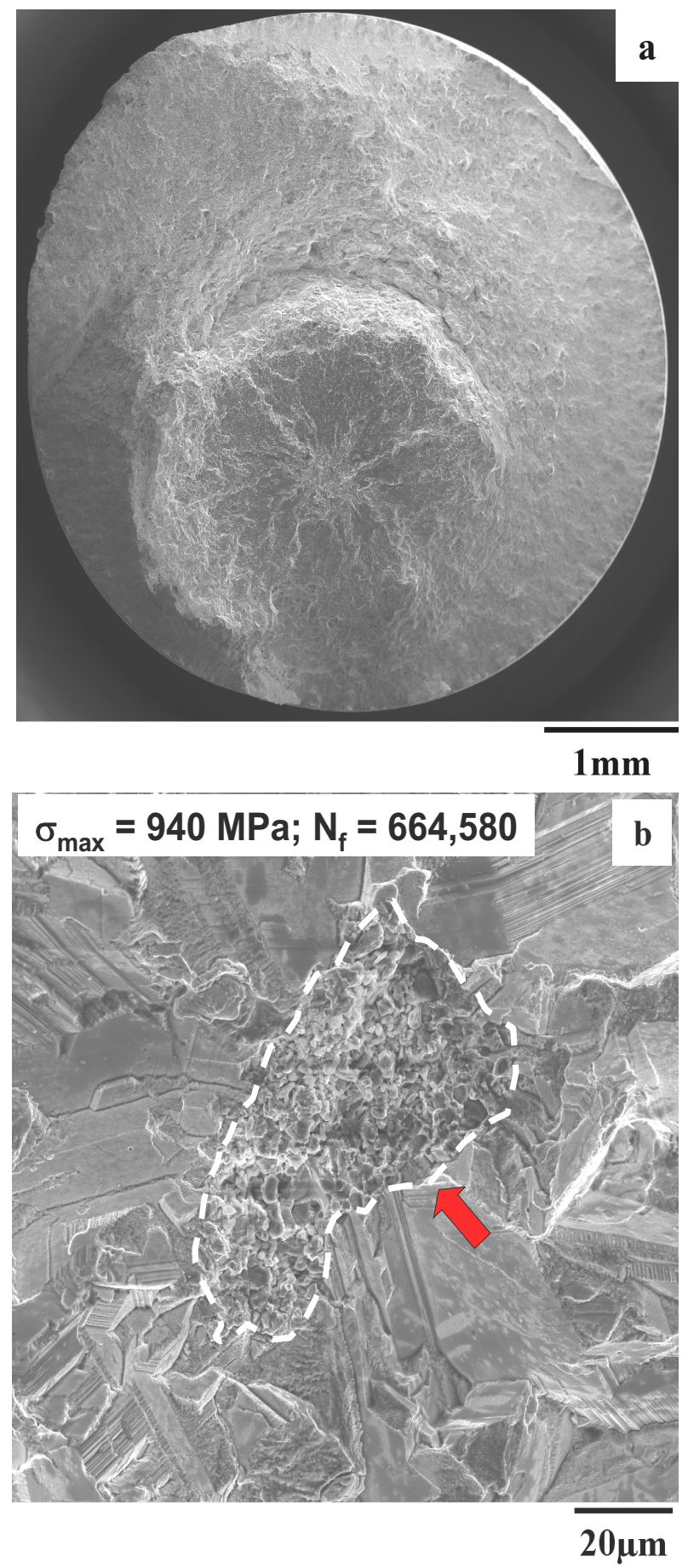
Fig 8: Fatigue fracture surface at $\sigma_{\max }=940 \mathrm{MPa}$ and $\mathrm{N}_{\mathrm{f}}=$ 664,580 ; (a) low magnification fractograph showing the crack origin location and (b) the crack nucleation area.

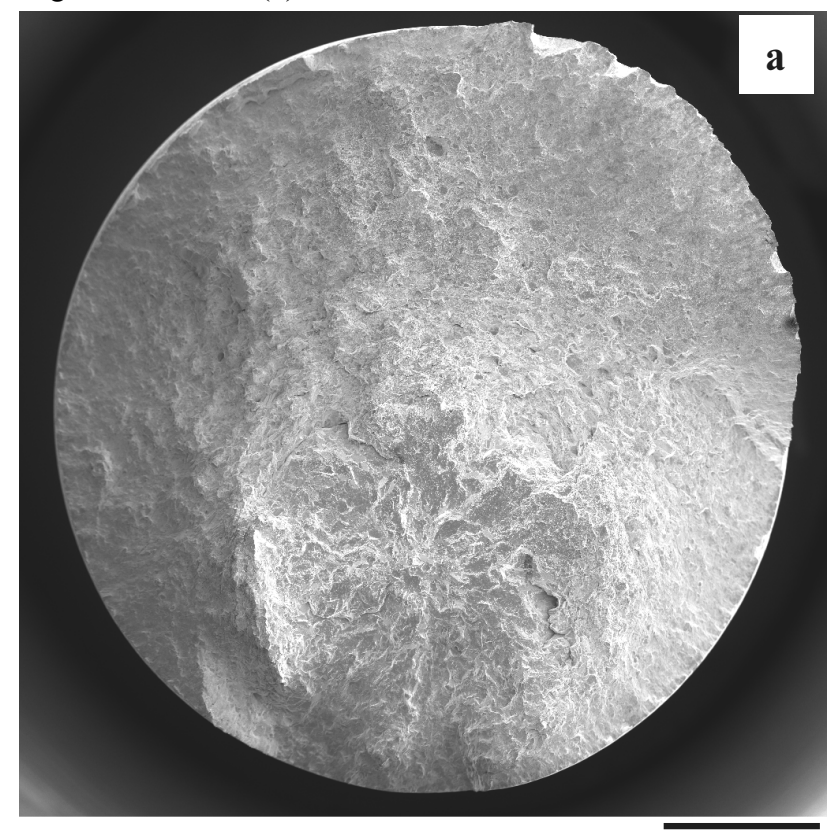

\section{$1 \mathrm{~mm}$}

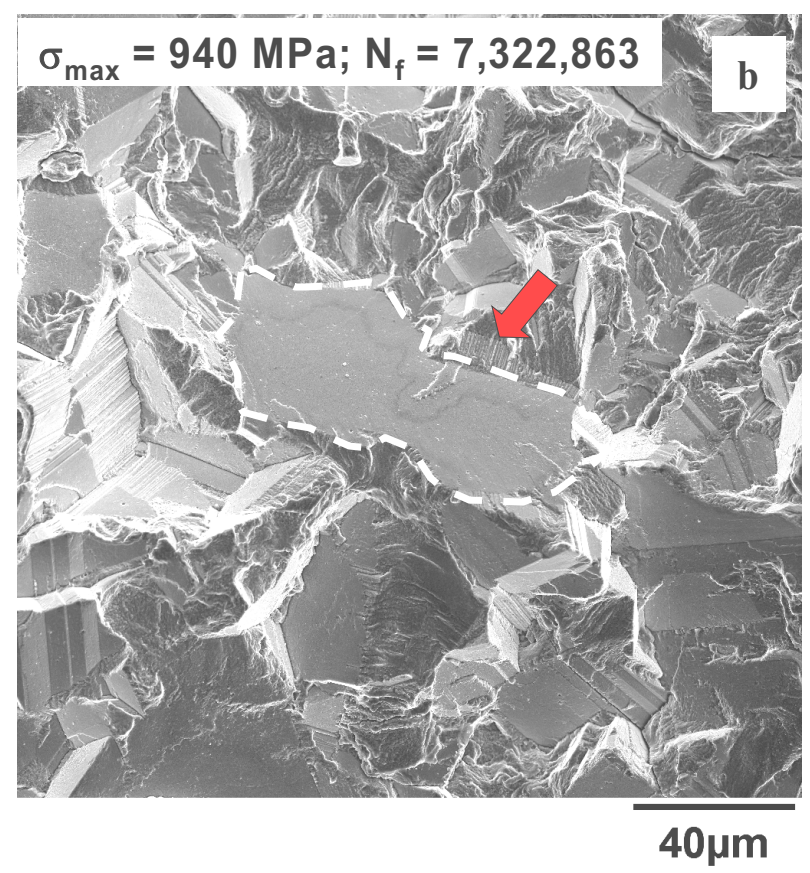

Fig 9: Fatigue fracture surface at $\sigma_{\max }=940 \mathrm{MPa}$ and $\mathrm{N}_{\mathrm{f}}=$ $7,322,863$; (a) low magnification fractograph showing the crack origin location and (b) the crack nucleation area.

at $940 \mathrm{MPa}$ differed by an order of magnitude (Figures 8 and 9), the values of $\mathrm{N}_{\mathrm{f}}$ were similar for the cases shown at $\sigma_{\max }=1000$ $\mathrm{MPa}$ (Figures 10 and 11). This suggests that the difference/similarity in life at $940 \mathrm{MPa} / 1000 \mathrm{MPa}$ was caused by the crack nucleation life.
Energy dispersive spectroscopic (EDS) analysis was done to determine the chemistry of the inclusion related CNA in one of the samples. The area was rich in $\mathrm{Al}$ and $\mathrm{O}$, when compared to the chemistry of a crystallographic facet on the same fracture surface.
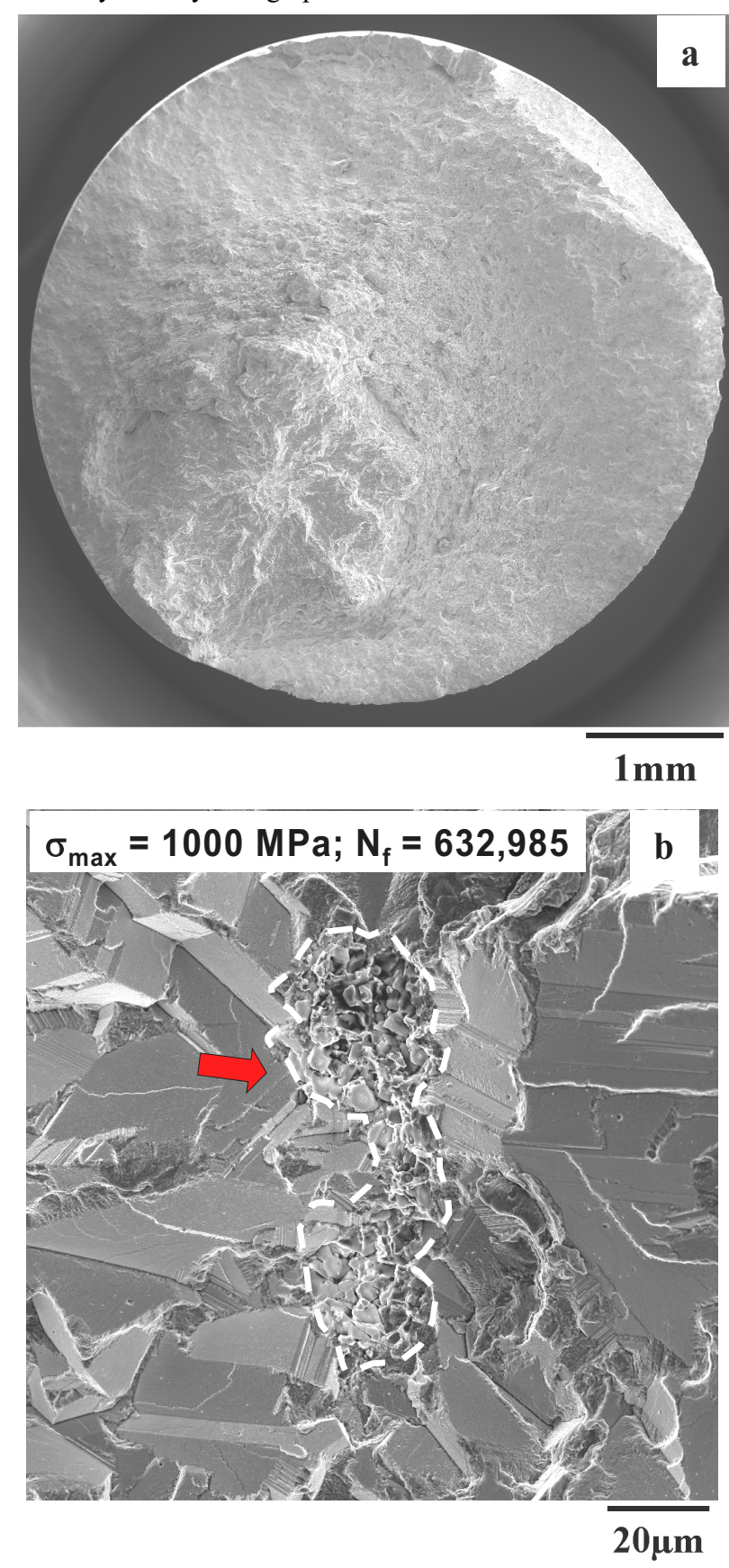

Fig 10: Fatigue fracture surface at $\sigma_{\max }=1000 \mathrm{MPa}$ and $\mathrm{N}_{\mathrm{f}}=$ 632,985 ; (a) low magnification fractograph showing the crack origin location and (b) the crack nucleation area

A study of inclusions on metallographic sections of the same material [17] indicated the presence of metallic (predominantly Al and some $\mathrm{Si}$ ) oxide type inclusions of similar sizes as the inclusion related CNAs on the fracture surfaces.

The distance of crack origin from the surface $\left(d_{n}\right)$ with respect to 
$\mathrm{N}_{\mathrm{f}}$ at $\sigma_{\max }$ levels of 940,1000 , and $1100 \mathrm{MPa}$ is shown in Figure 12. The points due to the crystallographic and the inclusion crack nucleation are distinguished. Although all tested specimens are not shown in the figure, there were more crystallographic failures than inclusion failures at 940 and $1000 \mathrm{MPa}$. There was no clear trend in terms of $d_{n}$ and the type of crack nucleation. Also, for a given stress level and type of crack nucleation, there was no clear dependence of $\mathrm{N}_{\mathrm{f}}$ on $\mathrm{d}_{\mathrm{n}}$.

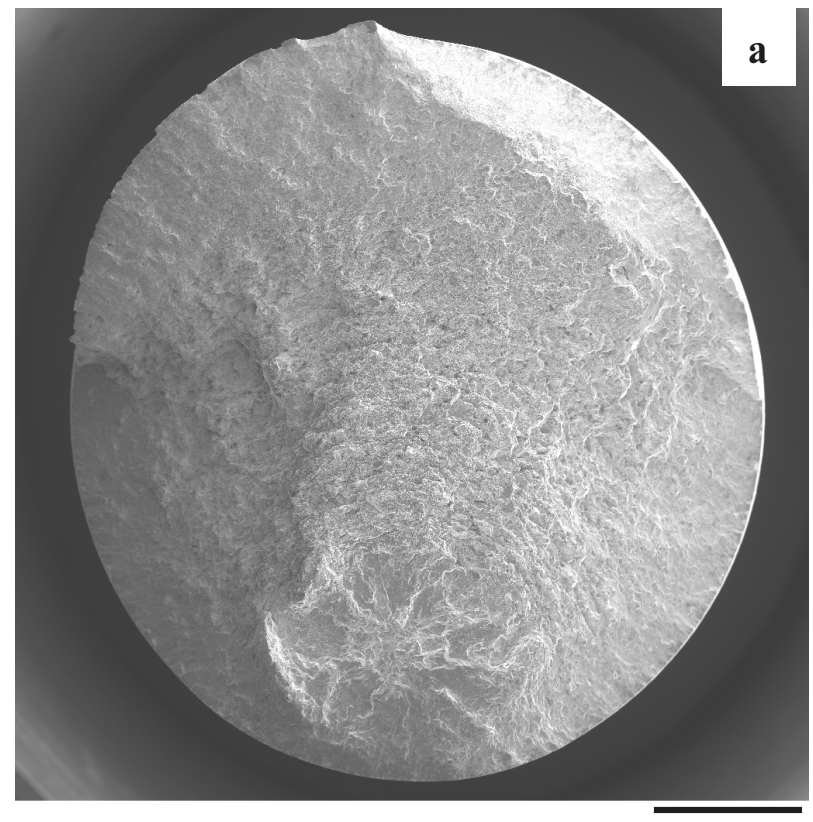

$1 \mathrm{~mm}$

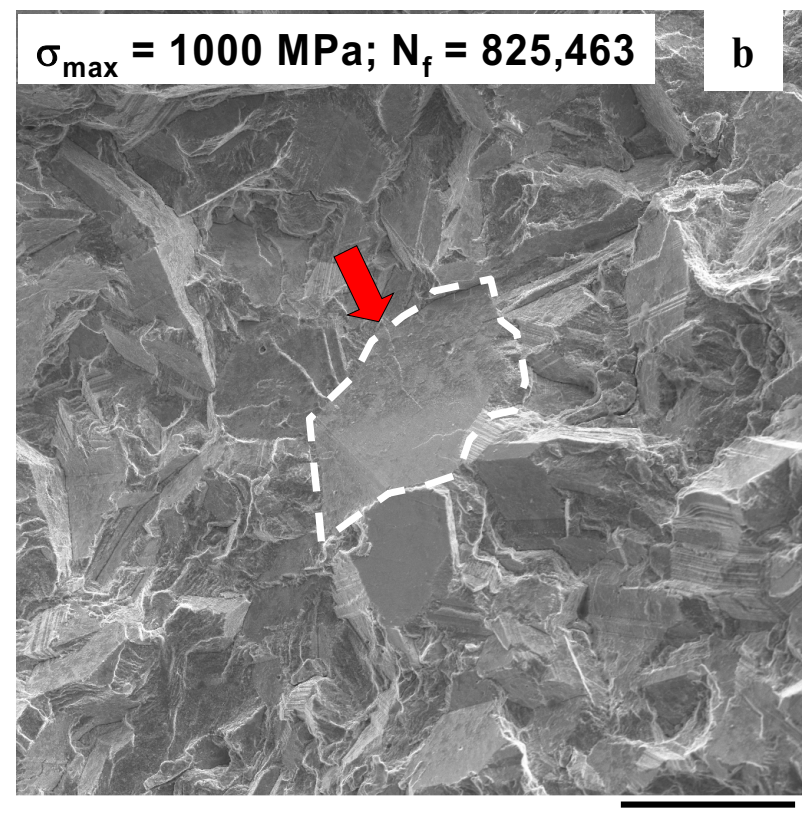

$60 \mu \mathrm{m}$

Fig 11: Fatigue fracture surface at $\sigma_{\max }=1000 \mathrm{MPa}$ and $\mathrm{N}_{\mathrm{f}}=$ 825,463 ; (a) low magnification fractograph showing the crack origin location and (b) the crack nucleation area

$\underline{\text { Variability in Life due to Divergence of Mechanisms }}$
The fatigue life behavior is plotted in Figure 13 with distinction between the inclusion and the crystallographic crack nucleation failures. At $\sigma_{\max }$ of $1100 \mathrm{MPa}$, the two types of failure overlap, indicating similar crack nucleation lives for both the inclusion and the crystallographic modes. This is because the crack growth life is not expected to introduce significant variability in life due to similar CNA sizes in both types of crack nucleation. Also, at $\sigma_{\max }$ $=1100 \mathrm{MPa}$, the scale of variability in the lives of the inclusion and the crystallographic failures were similar. Lives of both types were on the order of 1 to $3 \times 10^{5}$ cycles. At $\sigma_{\max }=1000 \mathrm{MPa}$, the variability in life increased. Although the inclusion and the crystallographic modes overlapped at this stress level, the lives of inclusion failures were within a narrower band (on the order of $4 \times 10^{5}$ to $6 \times 10^{5}$ cycles) compared to the crystallographic failures, which had a higher degree of variability (on the order of $4 \times 10^{5}$ to $2.5 \times 10^{6}$ cycles). At $\sigma_{\max }=940 \mathrm{MPa}$, the variability increased further when compared to $\sigma_{\max }=1000 \mathrm{MPa}$. However, the lifetimes segregated at this stress level into low lives (on the order of $10^{5}$ cycles) and high lives (on the order of $10^{7}$ cycles). The increase in variability, therefore, was due to a divergence of mechanisms. The low life failures were dominated by the inclusion crack nucleation and the high life failures resulted exclusively from crystallographic crack nucleation. It is also clear that all the inclusion failures occurred within a narrow band at all stress levels with lives on the order of $10^{5}$ to $10^{6}$ cycles. The fatigue behavior of Rene' 88 DT can therefore be described as a superposition of two mechanisms which overlap at higher stress levels and diverge as the stress level is decreased. This is schematically shown in Figure 13 by the hatched areas. It is proposed that the apparent increase in the variability in life with decreasing stress level was due to this divergence between the lives of the two mechanisms.

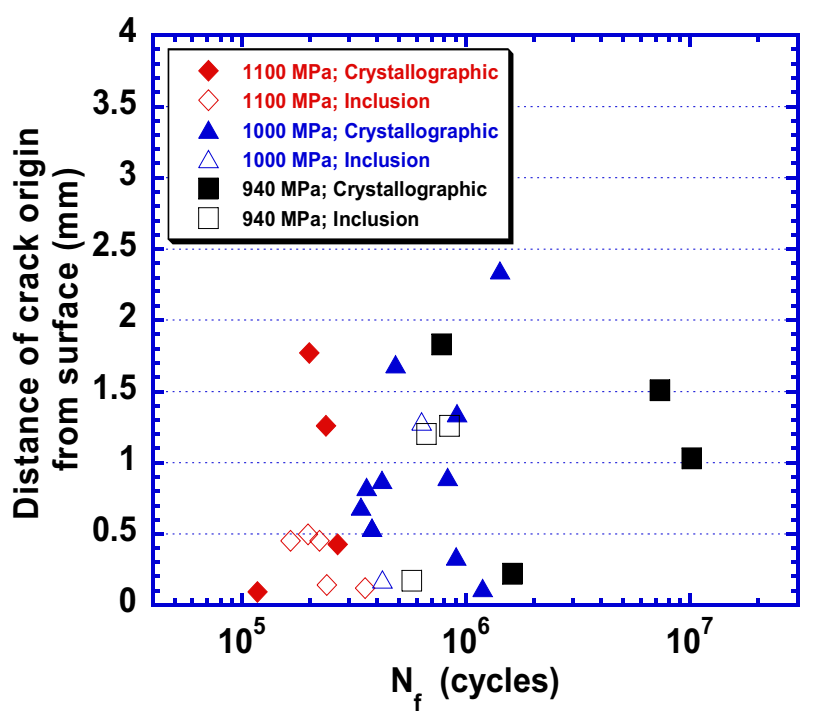

Fig 12: Dependence of life on the distance of crack origins from the sample surface

Role of Crack Nucleation vs. Growth in Divergence of Life. Figure 13 seems to indicate that the lower life mechanism (shown by horizontal hatching) was dominated by the crack growth life. However, the divergence in the lives of the two mechanisms was caused by an increase in the difference between their crack 
nucleation lives with decreasing stress level. This can also be shown by crack growth life calculations. Since failure occurred by subsurface crack nucleation at the selected stress levels, crack growth was essentially in vacuum. Therefore, crack growth data

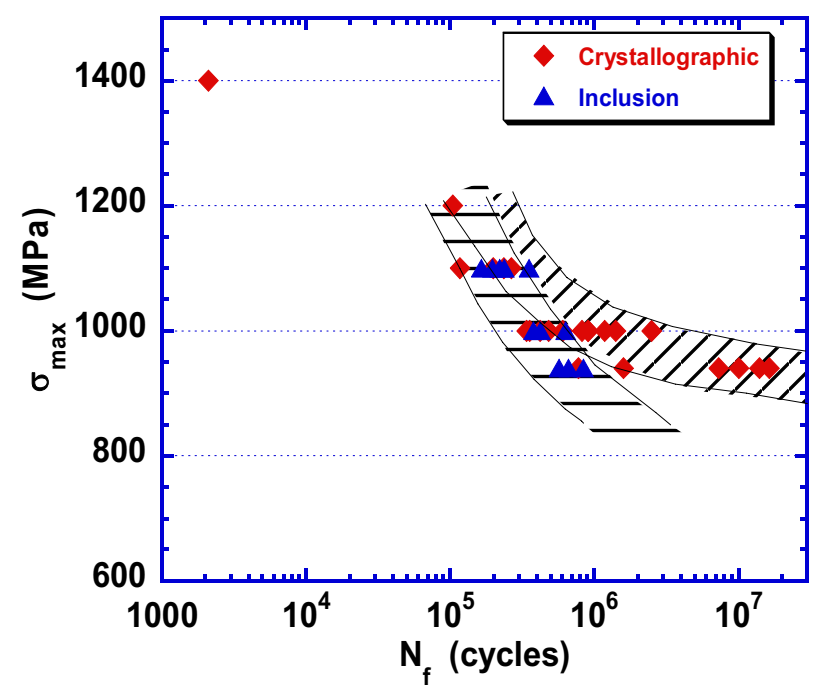

Fig 13: Divergence of superimposing mechanisms causing the increase in variability in lives.

were obtained in vacuum and are presented in Figure 14 in terms of da/dN vs. $\Delta \mathrm{K}$. The crack growth rates in the lab air at the same conditions are also shown for comparison. Clearly, the growth rates decreased considerably in vacuum, especially in the nearthreshold regime. The difference in the crack growth threshold, $\Delta \mathrm{K}_{\text {th }}$, between the vacuum and the lab air was about $3 \mathrm{MPa} \sqrt{\mathrm{m}}$. The small-crack behavior was not studied here. Luo \& Bowen [18] reported a significant small-crack effect in their study on another $\mathrm{P} / \mathrm{M}$ superalloy with slightly smaller grain size than the present case. To the authors' knowledge there are no small-crack studies in Rene' 88 DT in the open literature. An approximate small-crack behavior was therefore assumed in the present case as shown by dashed lines in Figure 14. The crack growth lives presented here should, therefore, be considered approximate. The purpose of these calculations was not to obtain accurate numbers but to determine the trend in the crack growth lives with respect to stress level and the starting crack size.

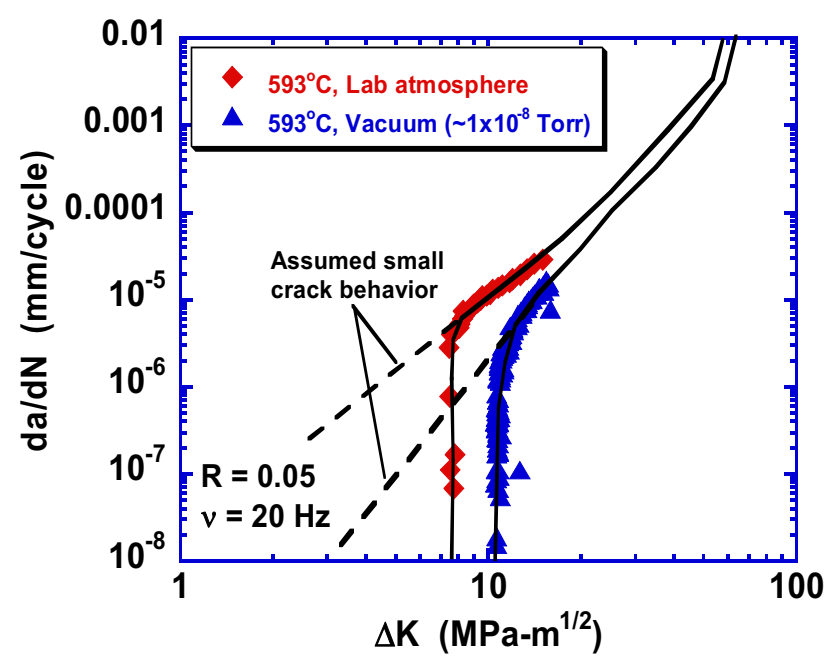

Fig 14: Fatigue crack growth behavior of Rene' 88 DT at $593^{\circ} \mathrm{C}$ in lab air and vacuum. The small crack behavior has been approximated as shown.

The crack nucleation regime can be defined as the formation of the CNA seen on the fracture surfaces. The starting crack size in the growth calculations can then be taken as the size of the CNA. This is a reasonable assumption and has been used in other studies $[19,20]$. In the case of inclusion related cracks, this means an additional assumption, i.e., the CNA size is equivalent to the size of the initial sharp crack [19]. As discussed earlier, the size of the CNA was similar for both the inclusion and the crystallographic crack nucleation. The stress intensity solution for an embedded elliptical crack [21] in a square cross-section bar of area $4.5 \mathrm{~mm}^{2}$ was used. The calculated crack growth lives are superimposed on the total life data in Figure 15. As indicated, the data band corresponds to starting half-crack sizes of 25 to $50 \mu \mathrm{m}$. As expected, the crack growth lives gradually increased with decreasing stress level and followed the increasing trend in the life of the lower-life mechanism (represented by horizontal hatching in the figure). Also, the variability in the crack growth lives did not change substantially with stress level. This is partly due to the linear approximation for the average small crack behavior (Fig. 14). Nevertheless it is clear that, the crack growth regime cannot account for the overall increase in the variability in lives with decreasing stress level. This further supports the proposed theory of divergent mechanism description of the fatigue behavior.

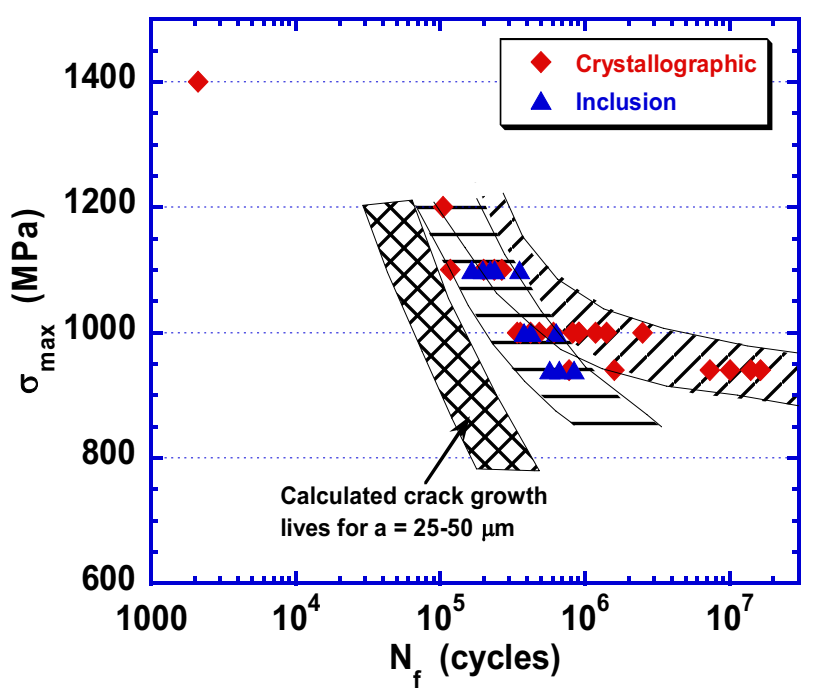

Fig 15: The role of crack growth in the lifetimes of the two divergent mechanisms

This study has shown that the true fatigue behavior of Rene' 88 DT may be composed of superimposed mechanisms that diverge with decreasing stress level. The conventional description of S-N behavior, i.e., in terms of single distribution can lead to an inaccurate assessment of variability in life. However, the description in terms of divergent mechanisms has the potential for more accurate life prediction and therefore, a reliable methodology for life extension. 


\section{Conclusions}

From this study of variability in fatigue behavior of Rene' 88 DT, the following conclusions can be made:

(i) The variability in fatigue lifetimes increased with decreasing stress level ranging from a factor of 3 at the stress level of $1100 \mathrm{MPa}$ to a factor approximately of 30 at $940 \mathrm{MPa}$.

(ii) All failures except the one at $\sigma_{\max }=1400 \mathrm{MPa}$ occurred by subsurface crack nucleation. Cracks nucleated either at an inclusion or across crystallographic plane.

(iii) The increase in variability was due to superposition of two mechanisms in the fatigue behavior, the lives of which diverged with decreasing stress level.

(iv) A mechanism-based treatment of variability has the potential for providing more accurate life prediction, thereby reducing unnecessary conservatism in current lifing methods.

\section{Acknowledgement}

The authors gratefully acknowledge the support of Dr. Leo Christodoulou of the Defense Advanced Research Projects Agency (DARPA) under DARPA Orders Q588-00.

\section{References}

[1] S. K. Jha, J. M. Larsen, A. H. Rosenberger and G. A. Hartman, "Dual Fatigue Failure Modes in Ti-6Al-2Sn-4Zr6Mo and Consequences on Probabilistic Life Prediction," Scripta Materialia, Vol. 48, pp. 1637-1642, 2003.

[2] S. K. Jha, J. M. Larsen, A. H. Rosenberger and G. A. Hartman, "Variability in Fatigue Life of Ti-6Al-2Sn-4Zr6Mo," In Press, Materials Science and Engineering A, 2004.

[3] S. K. Jha, J. M. Larsen, and A. H. Rosenberger, "Tracking Fatigue Life Variability of a Nearly Fully Lamellar $\gamma$-TiAl Based Alloy," in preparation for Materials and Metallurgical Transactions A, 2004.

[4] D. R. Chang, D. D. Krueger, and R. A. Sprague, "Superalloy Powder Processing, Properties and Turbine Disk Applications," in Superalloys 1984, pp. 245-273, 1984.

[5] E. S. Huron and P. G. Roth, "The Influence of Inclusions on Low Cycle Fatigue Life in a P/M Nickel-Base Disk Superalloy," in Superalloys 1996, Edited by R. D. Kissinger, D. J. Deye, D. L. Anton, A. D. Cetel, M. V. Nathal, T. M. Pollock, and D. A. Woodford, The Minerals, Metals, and Materials Society, pp. 359-368, 1996.

[6] J. M. Hyzak and I. M. Bernstein, "The Effect of Defects on the Fatigue Crack Initiation Process in Two P/M Superalloys: Part I. Fatigue Origins," Metallurgical Transactions A, Vol. 13A, pp. 33-43, 1982.

[7] J. M. Hyzak and I. M. Bernstein, "The Effect of Defects on the Fatigue Crack Initiation Process in Two P/M Superalloys: Part II. Surface-Subsurface Transition," Metallurgical Transactions A, Vol. 13A, pp. 45-52, 1982.

[8] S. T. Wlodek, M. Kelly, and D. A. Alden, "The Structure of Rene' 88 DT," in Superalloys 1996, Edited by, R. D. Kissinger, D. J. Deye, D. L. Anton, A. D. Cetel, M. V. Nathal, T. M. Pollock, and D. A. Woodford, The Minerals, Metals, and Materials Society, pp. 129-136, 1996.

[9] E. S. Huron, "Serrated Yielding in a Nickel-Base Superalloy," in Superalloys 1992, Edited by S. D.
Antolovich, R. W. Stusrud, R. A. MacKay, D. L. Anton, T. Khan, R. D. Kissinger, and D. L. Klarstrom, The Minerals, Metals, and Materials Society, pp. 675-684, 1992.

[10] K. B. S. Rao, S. Kalluri, G. R. Halford, M. A. McGaw, "Serrated Flow and Deformation Substructure at Room Temperature in Inconel 718 Superalloy During Strain Controlled Fatigue," Scripta Metallurgica et Materialia, Vol. 32, No. 4, pp. 493-498, 1995.

[11] D. Eylon and J. M. Hyzak, "An Investigation of Fatigue Origins in Superalloy Compacts," Metallurgical Transactions A, Vol. 9A, pp. 127-129, 1978.

[12] A. de Bussac, "Prediction of the Competition Between Surface and Internal Fatigue Crack Initiation in PM Alloys," Fatigeu Fract. Engng Mater. Struct., Vol. 17, No. 11, pp. 1319-1325, 1994.

[13] P.E. Magnusen, R. J. Bucci, A. J. Hinkle, J. R. Brokenbrough, and H. J. Konish, Int J. Fatigue, Vol. 19, pp. S275, 1998 .

[14] P. J. Laz, B. A. Craig, and B. M. Hillberry, Int. J Fatigue, Vol. 23, pp. S119, 2001.

[15] S. K. Sasaki, Y. Ochi, A. Ishii, Engng. Fract Mech, Vol. 28, pp. 761, 1987.

[16] M. Goto, Fatigue Fract. Engng. Mater. Struct., Vol. 17, pp. $635,1994$.

[17] K. Li and A. H. Rosenberger, Personal communication / Unpublished Data, 2004.

[18] J. Luo and P. Bowen, "Small and Long Fatigue Crack Growth Behaviour of a PM Ni-Based Superalloy, Udimet 720,” Int. J. Fatigue, Vol. 26, pp. 113-124, 2004.

[19] J. Luo and P. Bowen, "Statistical Aspects of Fatigue Behavior in a PM Ni-base Superalloy Udimet 720," Acta Materialia, Vol. 51, pp. 3521-3535, 2003.

[20] J. Luo and P. Bowen, "A Probabilistic Methodology for Fatigue Life Prediction," Acta Materialia, Vol. 51, pp. 3537-3550, 2003.

[21] J. C. Newman and I. S. Raju, "Stress Intensity Factor Equations for Cracks in Three Dimensional Bodies Subjected to Tension and Bending Loads," in Computational Methods in the Mechanics of Fracture, Chapter 9, Elsevier Science Publishers, 1986. 